\title{
Cytotoxicity of graphene oxide and graphene oxide loaded with doxorubicin on human multiple myeloma cells
}

This article was published in the following Dove Press journal:

International Journal of Nanomedicine

14 March 2014

Number of times this article has been viewed

\author{
Shaoling $\mathrm{Wu}^{\prime}$ \\ Xindong Zhao ${ }^{2}$ \\ Zhongguang Cui' \\ Chunting Zhao' \\ Yuzhen Wang' \\ Li Du' \\ Yanhui Li ${ }^{3}$
}

'Department of Hematology, The Affiliated Hospital of Medical

College, Qingdao University, Qingdao, Shandong, People's Republic of China;

${ }^{2}$ Department of Hematology, Medical College of Qingdao University,

Qingdao, Shandong, People's

Republic of China; ${ }^{3}$ Laboratory of

Fiber Materials and Modern Textile,

The Growing Base for State Key

Laboratory, Qingdao University,

Qingdao, Shandong, People's Republic of China
Correspondence: Xindong Zhao 38 Dengzhou Road, Qingdao, Shandong 26602I, People's Republic of China Tel +8653283780030

Email qdzhaoxindong@163.com

Yanhui Li

308 Ningxia Road, Qingdao, Shandong

26607I, People's Republic of China

Tel +8653285951842

Email liyanhui@tsinghua.org.cn

\begin{abstract}
The purpose of this study was to evaluate the cytotoxicity of human multiple myeloma cells (RPMI-8226) treated with graphene oxide (GO), doxorubicin (DOX), and GO loaded with DOX (GO/DOX). Cell viability was determined using the Cell Counting Kit-8 assay and analyzing the cell cycle and cell apoptosis. Cells treated with GO, GO/DOX, and pure DOX for 24 hours showed a decrease in proliferation. GO/DOX significantly inhibited cell proliferation as compared with pure DOX $(P<0.01)$. When the effects of GO were removed, there was no observed difference between GO/DOX and pure DOX $(P>0.05)$. Flow cytometry analysis of untreated and GO-, DOX-, and GO/DOX-treated cells found no significant differences in the $\mathrm{G}_{0} / \mathrm{G}_{1}$ phase $(P>0.05)$, while significant differences were observed in the total apoptotic rates $(P<0.05)$. No significant differences existed in the total apoptotic rates of GO-treated and untreated cells $(P>0.05)$. These findings suggest that GO caused low cytotoxicity and did not induce cell apoptosis or change the cell cycle in multiple myeloma cells. Moreover, GO did not affect the antitumor activity of DOX. In conclusion, GO would be suitable as an anticancer drug nanocarrier and used to treat hematological malignancies.
\end{abstract}

Keywords: graphene oxide, doxorubicin, human multiple myeloma cell, CCK-8, cell cycle, cell apoptosis

\section{Introduction}

Multiple myeloma (MM) is the second most common hematological malignancy and is characterized by an expansion of abnormal plasma cells in the bone marrow and excessive production of monoclonal immunoglobulin, which often leads to pathologic fractures and hematopoietic function failure. ${ }^{1}$ The average survival rate of patients with advanced untreated MM is 6 months, while treatment with conventional chemotherapy increases survival to under 3 years. Overall survival remains approximately $30 \%$ at 10 years. $^{2}$ Transplantation treatment increases survival rates and may be considered an effective strategy, ${ }^{3}$ but the prognosis remains poor. MM is still considered an incurable disease, ${ }^{4}$ and new ways to improve the prognosis of MM patients are urgently needed.

Doxorubicin (DOX) plays an important role in the treatment of MM. It is a highly effective antitumor antibiotic used in human cancer chemotherapy; ${ }^{5}$ however, it can cause cardiotoxicity, ${ }^{6}$ hepatotoxicity, ${ }^{7}$ and nephrotoxicity. ${ }^{8}$ To reduce the side effects and improve the efficacy of drugs, research on drug carriers and synthetic nanodrugs has become the focus of modern medical research. Currently, several nanodrugs, such as Caelyx ${ }^{\circledR 9}$ (Schering-Plough, Kenilworth, NJ, USA) and Doxil $\mathrm{R}^{\circledR}$ (Centocor Ortho Biotech, Inc., Horshan, PA, USA) injections (liposomal DOX), are approved for use 
in clinics. It is expected that nanodrugs will be used to treat various types of diseases.

Graphene oxide (GO) is a novel carbon nanomaterial with tremendous potential in material ${ }^{10-12}$ and medical ${ }^{13,14}$ science given its unique physical, chemical, and mechanical properties. Recent studies have found great popularity for GO as a drug carrier, ${ }^{14,15}$ imaging probe, ${ }^{16}$ and biomedical device. ${ }^{15,17}$ Our previous study, along with other studies, found DOX, a common antitumor drug model, adsorbed to the surface of GO by $\pi-\pi$ stacking ${ }^{18,19}$ and hydrogen bonding, ${ }^{18,20,21}$ suggesting that GO may be suitable as a nanodrug carrier. ${ }^{18}$ However, risk assessment of GO is severely lacking, and an urgent demand for identifying the potential hazards of GO remains. It was recently found that both graphene and GO cause low toxicity in cells, including macrophages, ${ }^{22,23}$ human stem cells, ${ }^{24}$ and normal human lung cells, ${ }^{25}$ although a few reports observed toxicity in adenocarcinoma cells (A549 cells) ${ }^{26}$ and fibrosarcoma cells (L929 cells). ${ }^{27}$ The in vivo pharmacokinetics and biodistribution of GO in mice was also studied. ${ }^{28,29}$ Very little is known about the cytotoxicity of GO and the antitumor effects of GO loaded with an anticancer drug on hematological tumor cells, and very few studies have assessed the cytotoxic potency of GO associated with cell apoptosis.

The objectives of the study were: 1) to investigate the toxic effects of GO on human MM cells (RPMI-8226), 2) to assess the antitumor effects of DOX and GO loaded with DOX (GO/DOX), and 3) to determine whether GO induces apoptosis and changes the cell cycle. Cell Counting Kit-8 (CCK-8), cell cycle, and cell apoptosis were measured.

\section{Materials and methods Chemicals}

GO (Go-L-L-NA) was purchased from Nanoon Nanomaterial and Technology Co, Ltd (Beijing, People's Republic of China); DOX was obtained from Zhejiang Hisun Pharmaceutical Co, Ltd (Zhejiang, People's Republic of China); fetal bovine serum (FBS) was purchased from Gibco (Gaithersburg, USA). RPMI-1640 medium, penicillin and streptomycin for cell culture was obtained from Beijing Zhongshan Golden Bridge Biological Technology Co, Ltd (Beijing, People's Republic of China). CCK-8 assay kits were obtained from Dojindo Laboratories (Kyushu, Japan). Cellcycle change detection kits were obtained from Beyotime Institute of Biotechnology (Jiangsu, People's Republic of China). Alexa Fluor ${ }^{\circledR} 488$ Annexin V/Dead Cell Apoptosis Kit (NO V13241) was purchased from Life Technologies (Carlsbad, CA, USA). All reagent water used in the laboratory was purchased from Qingdao Distilled Water Plant (Shandong, People's Republic of China).

\section{Cell culture}

Human MM RPMI-8226 cells were obtained from the American Type Culture Collection (Manassas, VA, USA). Cells were grown in cell culture flasks containing RPMI-1640 medium supplemented with $1 \%$ penicillin, $1 \%$ streptomycin, and $10 \%(\mathrm{v} / \mathrm{v}) \mathrm{FBS}$ and kept in a humidified incubator at $37^{\circ} \mathrm{C}$ with $5 \% \mathrm{CO}_{2}$. Cells were passaged every 2-3 days: cells were collected in $15 \mathrm{~mL}$ tubes and centrifuged for 5 minutes at $1,000 \times g$ and the supernatant removed and replaced with fresh medium. After DOX was completely dissolved in sterile water, it could be distributed in the complete medium containing $10 \%$ FBS uniformly and was stable in serum supplemented medium.

\section{Analysis of cell viability}

Cell viability was assessed using the CCK-8 assay in a microplate reader. RPMI-8226 cells were seeded in 96-well microplates (Corning Technologies, Corning, NY, USA) at a density of $1.5 \times 10^{5}$ cells $/ \mathrm{mL}$ in $100 \mu \mathrm{L}$ RPMI-1640 medium containing $10 \%$ FBS for 24 hours. Cells were then cultured in medium with various concentrations of GO for 24 hours. Control cells did not receive any GO treatment. Three replicate wells were used for the control and test concentrations. Ten microliters of CCK-8 was added to each well, and the microplate was incubated at $37^{\circ} \mathrm{C}$ for 2 hours in a $5 \% \mathrm{CO}_{2}$ humidified incubator. The absorbance was then measured at $450 \mathrm{~nm}$ using a microplate reader (Spectrafluor; Tecan, Männedorf, Switzerland). Cell viability was expressed as a percentage of the control cell culture value. A control was performed in parallel to monitor the influence of RPMI-1640 medium on the assays. The cell viability was calculated as follows:

$$
\text { Cell viability }=\frac{\mathrm{OD}(\text { test })-\mathrm{OD}(\text { blank })}{\mathrm{OD}(\text { control })-\mathrm{OD}(\text { blank })} \times 100
$$

\section{Flow cytometry analysis of the cell cycle}

RPMI-8226 cells were prepared at a concentration of $5.0 \times 10^{5}$ cell $/ \mathrm{mL}$ and then seeded at a density of $1.0 \times 10^{6} \mathrm{cells} / \mathrm{well}$ in 6-well cell culture plates, treated with the indicated concentrations of GO, DOX, and GO/DOX (Fourier transform infrared spectrum of GO/DOX confirmed the effective loading of DOX on GO), ${ }^{18}$ and cultured for 24 hours at $37^{\circ} \mathrm{C}$ in a $5 \% \mathrm{CO}_{2}$ humidified incubator. Cells were harvested by centrifugation at $1,000 \times g$ for 5 minutes at room temperature, washed twice 
with ice-cold phosphate buffered saline (PBS), and fixed with $70 \%$ ethanol at $4^{\circ} \mathrm{C}$ overnight. The fixed cells were suspended in PBS and further treated with propidium iodide (PI) for 30 minutes at $37^{\circ} \mathrm{C}$ in the dark. The cells were then centrifuged at $1,000 \times g$, and the number of cells at the different phases of the cell cycle was analyzed using flow cytometry (Cytomic ${ }^{\mathrm{TM}}$ FC500; Beckman Coulter, Miami, FL, USA) equipped with the SYSTEM II ${ }^{\text {TM }}$ analysis software (Multicycle AV for Windows). In cell-cycle analysis, the RPMI-8226 cells were gated on linear forward scatter and linear side scatter in order to remove fragments or impurities.

\section{Flow cytometry analysis of cell apoptosis}

RPMI-8226 cells were prepared at a concentration of $6.0 \times 10^{5}$ cells $/ \mathrm{mL}$ and then seeded at a density of $1.2 \times 10^{6}$ cells/well in 6-well cell culture plates, treated with the indicated concentrations of GO, DOX, and GO/DOX, and cultured for 24 hours at $37^{\circ} \mathrm{C}$ in a $5 \% \mathrm{CO}_{2}$ humidified incubator. Cells were collected by centrifuging at $1,000 \times g$ for 5 minutes at room temperature and washing twice with ice-cold PBS. The cell density was calculated and the cells resuspended in $1 \times$ annexin-binding buffer to obtain a final density of $1 \times 10^{6}$ cells $/ \mathrm{mL}$. One-hundred microliters of the cell solution was placed into $1.5 \mathrm{~mL}$ Eppendorf tubes and $5 \mu \mathrm{L}$ annexin V-fluorescein isothiocyanate (FITC) and $1 \mu \mathrm{L}$ PI (100 $\mu \mathrm{g} / \mathrm{mL}$ ) working solution added. The RPMI-8226 cells were incubated at room temperature for 15 minutes. After incubation, $400 \mu \mathrm{L}$ of $1 \times$ annexin-binding buffer was added, gently mixed, and the samples kept on ice. The DNA (deoxyribonucleic acid) content of the cells was analyzed by flow cytometry (Cytomic ${ }^{\mathrm{TM}}$ FC500). All testing was required to be completed within an hour.

\section{Statistical analysis}

Three replicates of each treatment concentration were performed for each analysis. Values were expressed as mean \pm standard deviation of three independent experiments. Comparisons between two groups were analyzed using oneway analysis of variance, with $P<0.05$ taken as statistically significant.

\section{Results}

\section{Effects of GO on cell viability}

RPMI-8226 cells were treated with different concentrations of GO for 24 hours, and the effect of GO on cell viability assessed using the CCK-8 assay. Treated cells showed a GO dose-dependent decrease in cell viability (Figure 1). The control had $100 \%$ viable cells. Increasing GO concentration from 10 to $100 \mathrm{mg} / \mathrm{L}$ decreased cell viability from $95.6 \%$ to $79.6 \%$, respectively. These results suggest that GO caused low cytotoxicity in RPMI-8226 cells.

\section{Effects of DOX and GO/DOX on MM cell morphology}

Morphological studies were performed to identify the mode of cell death in MM cells. The morphology of untreated,

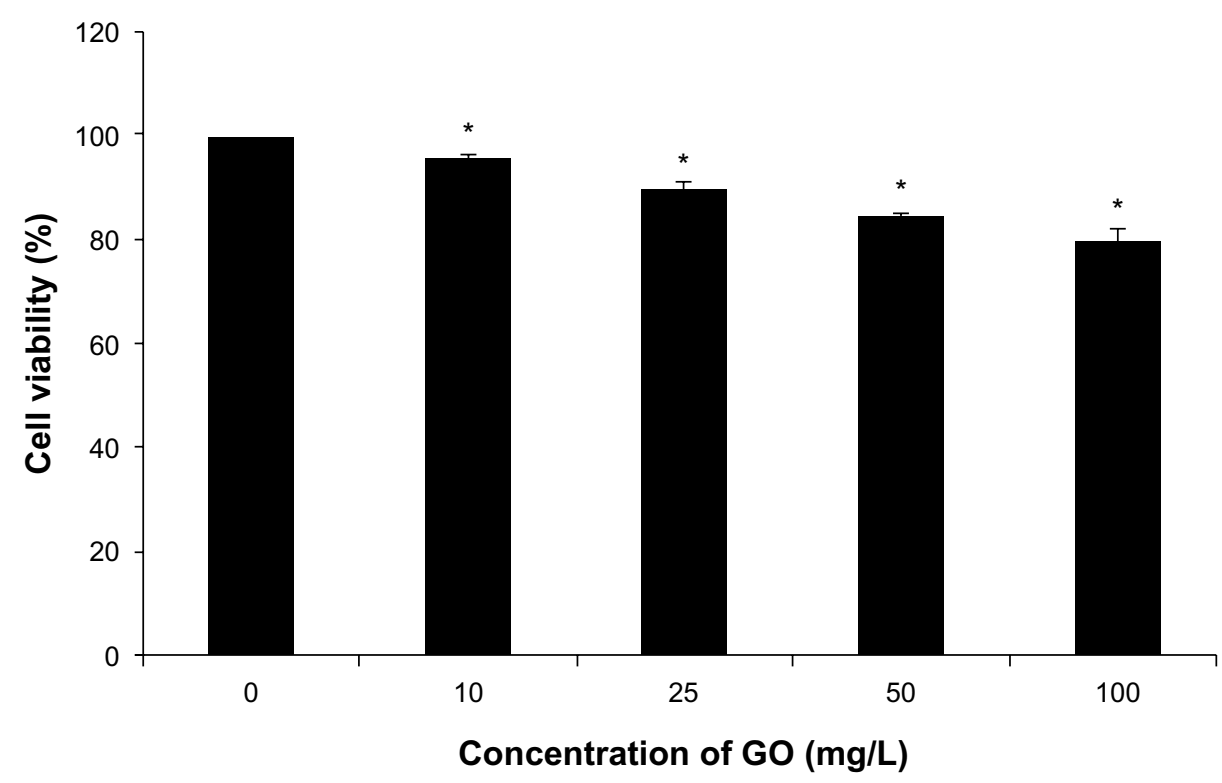

Figure I The effect of GO (I0, 25, 50, and $100 \mathrm{mg} / \mathrm{L}$; size $<100 \mathrm{~nm})$ on cell viability of RPMI-8226 cells for 24 hours.

Notes: Each bar represents the mean \pm SD of three independent experiments. $* P<0.05$ denotes significant differences between mean values measured in the GO group and those in control group.

Abbreviations: GO, graphene oxide; SD, standard deviation. 

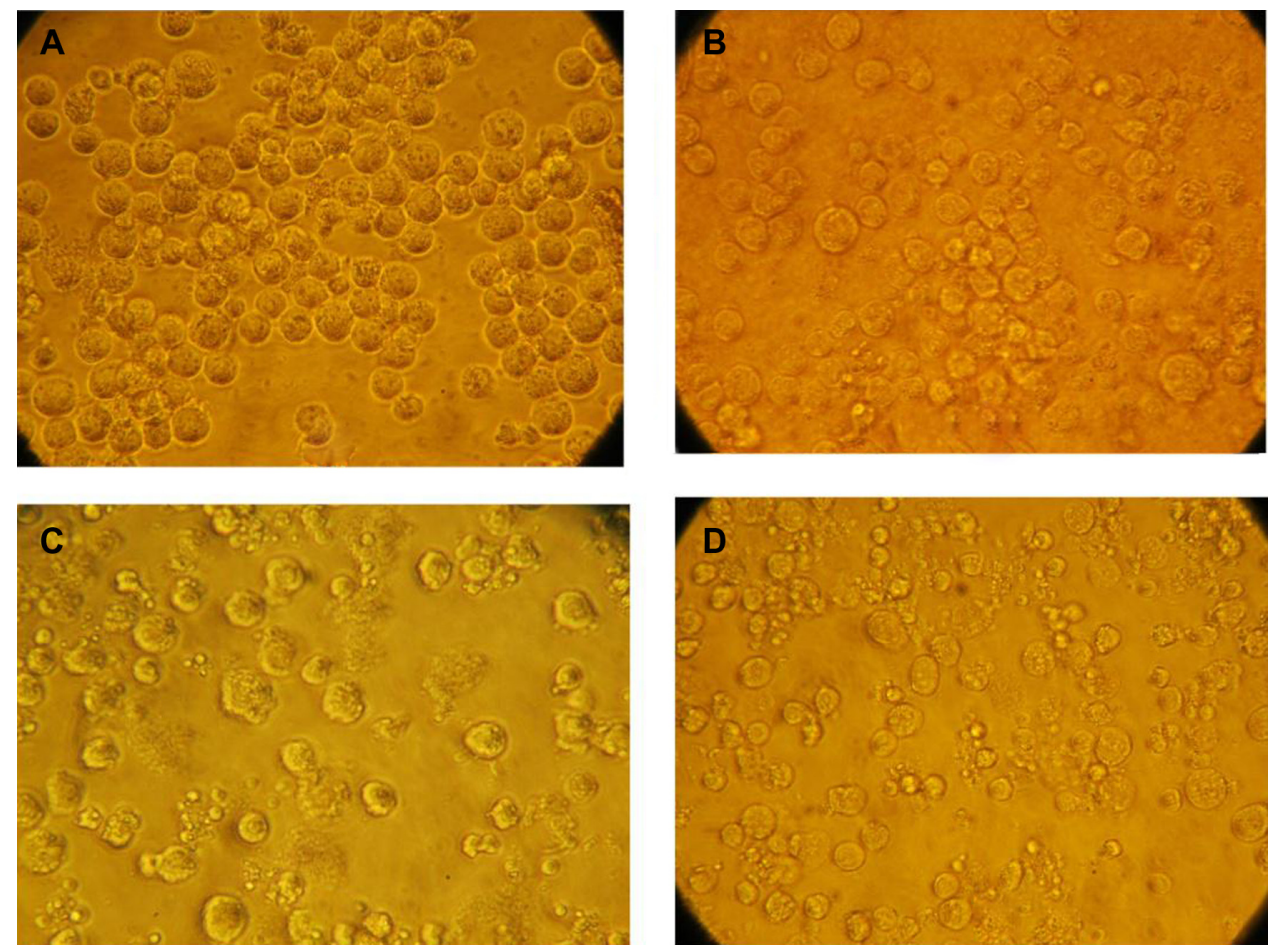

Figure 2 Morphology of RPMI-8226 cells treated with different drugs. Cells were treated for 24 hours with control (0 mg/L) (A), GO (50 mg/L) (B), DOX (2 mg/L) (C), and GO/DOX (GO $50 \mathrm{mg} / \mathrm{L}$ + DOX $2 \mathrm{mg} / \mathrm{L}$ ) (D).

Note: Images were taken at $400 \times$.

Abbreviations: DOX, doxorubicin; GO, graphene oxide; GO/DOX, GO loaded with DOX.

GO-treated, DOX-treated, and GO/DOX-treated cells was monitored by optical microscope at 24 hours. Untreated cells were round and large, with a bright cytoplasm and good refraction (Figure 2A). GO-treated cells were round with evidence of cell shrinkage and a translucent cytoplasm (Figure 2B). DOX-treated cells exhibited typical apoptotic features, such as membrane blebbing and cell shrinkage (Figure 2C). GO/DOX-treated cells showed significant morphological changes, including cell shrinkage (Figure 2D). These results suggest that DOX and GO/ DOX might have induced apoptosis in RPMI-8226 cells but not GO.

\section{Effects of DOX and GO/DOX on cell viability}

RPMI-8226 cells were treated with DOX (2 mg/L) and GO/DOX (GO $50 \mathrm{mg} / \mathrm{L}+$ DOX $2 \mathrm{mg} / \mathrm{L}$ ) for 24 hours, and the cell viability effects assessed using the CCK- 8 assay. Treated cells showed an obvious decrease in cell viability (Figure 3), with the cell viability of GO/DOX-treated cells significantly $(P<0.01)$ inhibited as compared with that of DOX-treated cells. However, when the effects of GO were excluded, there was no difference between GO/DOX and pure DOX $(P>0.05)$. These results suggest that GO did not influence the antitumor effects of DOX but may have rapidly adsorbed onto DOX via the unique one-atom-thick structure, hydrogen bonding, electrostatic interaction, and $\pi-\pi$ stacking interaction. ${ }^{18-21}$

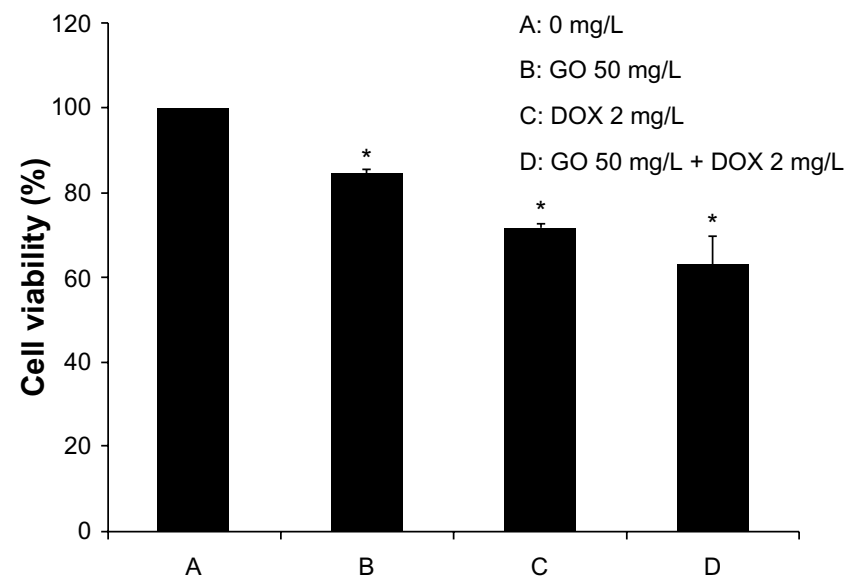

Figure 3 The effect of GO, DOX, and GO/DOX on cell viability of RPMI-8226 cells for 24 hours.

Notes: Each bar represents the mean \pm SD of three independent experiments. $* P<0.05$ denotes significant differences between mean values measured in the $\mathrm{GO}$, DOX, and GO/DOX groups and that in the control group.

Abbreviations: DOX, doxorubicin; GO, graphene oxide; GO/DOX, GO loaded with DOX; SD, standard deviation. 


\section{Cell-cycle analysis}

Cell-cycle analysis was performed in GO-, DOX-, and GO/ DOX-treated RPMI-8226 cells by flow cytometry. The fluorescence activated cell sorting (FACS) analyses of untreated cells showed $36 \% \mathrm{G}_{0} / \mathrm{G}_{1}$ phase population (Figure 4 ). GO- (GO $50 \mathrm{mg} / \mathrm{L}$ ), DOX- (DOX $2 \mathrm{mg} / \mathrm{L}$ ), and GO/DOX(GO $50 \mathrm{mg} / \mathrm{L}+$ DOX $2 \mathrm{mg} / \mathrm{L}$ ) treated cells at 24 hours showed minimal difference with $30.4 \%, 30.5 \%$, and $25.3 \%$ $\mathrm{G}_{0} / \mathrm{G}_{1}$ phase population, respectively (Figures 4 and 5). When compared, the GO/DOX and DOX groups showed no statistically significant differences $(P>0.05)$. These results clearly indicate that there was no change in the cell population at the $\mathrm{G}_{0} / \mathrm{G}_{1}$ phase in GO-, DOX-, and GO/DOX-treated cells. The $\mathrm{G}_{0} / \mathrm{G}_{1}$ population was expressed as a percentage of the total number of cells.

\section{Effect of GO on cell apoptosis}

The above results suggest that GO caused low cytotoxicity in RPMI-8226 cells, so annexin V-FITC/PI staining by flow cytometry was used to determine the effects of GO on cell apoptosis. RPMI-8226 cells were treated with different concentrations of GO for 24 hours. The treated cells were then collected, washed, and stained with PI and annexin V-FITC. The results showed a cell apoptotic rate of $5.1 \%$ in the control, $4.6 \%$ in the $10 \mathrm{mg} / \mathrm{L} \mathrm{GO}, 5.0 \%$ in the $50 \mathrm{mg} / \mathrm{L} \mathrm{GO}$, and $5.1 \%$ in the $100 \mathrm{mg} / \mathrm{L}$ GO groups (Figure 6), respectively. There were no significant differences in the cell apoptotic rate between the untreated and GO-treated cells. These results indicate that GO might not have induced cell apoptosis.

\section{Effect of DOX and GO/DOX \\ on apoptosis}

RPMI-8226 cells were treated with GO $50 \mathrm{mg} / \mathrm{L}$, DOX $2 \mathrm{mg} / \mathrm{L}$, and GO $50 \mathrm{mg} / \mathrm{L}+\mathrm{DOX} 2 \mathrm{mg} / \mathrm{L}$ for 24 hours, and cell apoptosis detected with annexin V-FITC/PI staining by flow cytometry. The observed apoptotic rates were 5.1\% in untreated, 5.0\% in GO-treated $(50 \mathrm{mg} / \mathrm{L}), 13.69 \%$ in DOX-treated $(2 \mathrm{mg} / \mathrm{L})$, and $14.2 \%$ in GO/DOX-treated (GO $50 \mathrm{mg} / \mathrm{L}+\mathrm{DOX} 2 \mathrm{mg} / \mathrm{L}$ ) cells, respectively (Figures 7 and 8). There was no statistical difference between the untreated and GO-treated cells ( $P>0.05$ ), suggesting that the decrease in cell viability caused by GO might not have been attributed to apoptosis. In contrast, there were significant differences between the apoptotic rates of untreated cells and that of DOX- and GO/DOX-treated cells $(P<0.05)$ but not between that of GO/DOX- and DOX-treated cells $(P>0.05)$. These results indicate that DOX could have induced cell apoptosis, and GO did not affect the ability of DOX to induce apoptosis.

\section{Discussion}

MM is a malignant proliferation of abnormal plasma cells. In recent years, the treatment of MM has improved rapidly

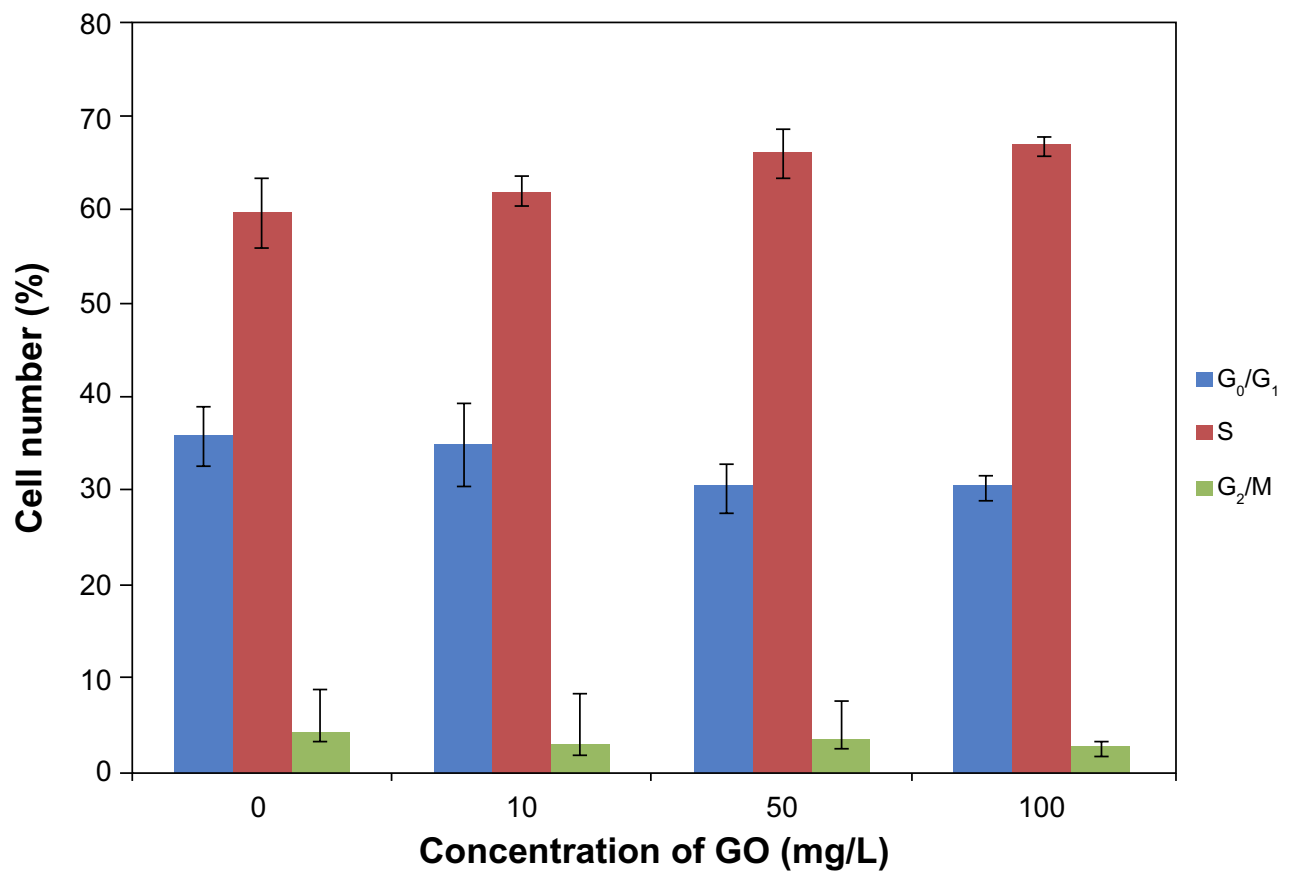

Figure 4 The effect of GO (10,50, and $100 \mathrm{mg} / \mathrm{L}$; size $<100 \mathrm{~nm})$ on cell cycle of RPMI-8226 cells for 24 hours. Note: Each bar represents the mean \pm SD of three independent experiments. Abbreviations: GO, graphene oxide; SD, standard deviation. 


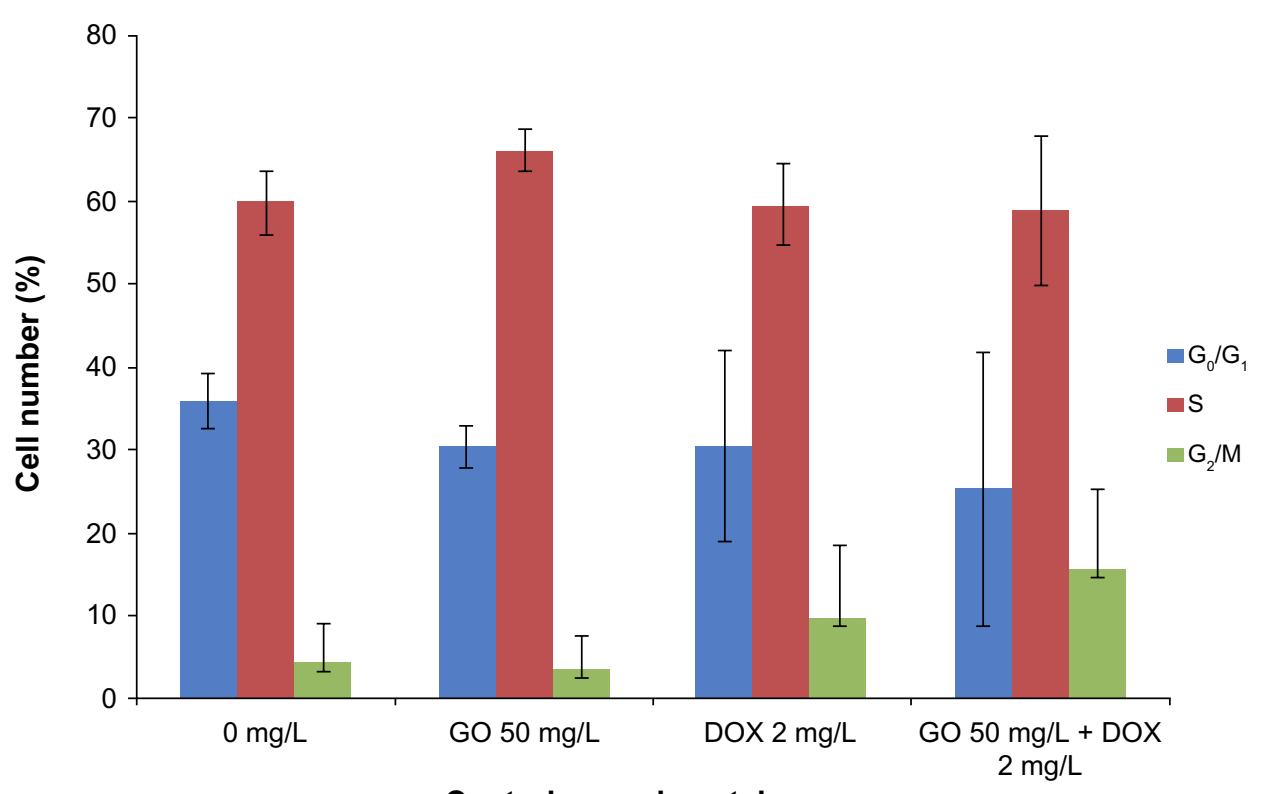

Figure 5 The effect of GO, DOX, and GO/DOX on the cell cycle of RPMI-8226 cells for 24 hours.

Note: Each bar represents the mean \pm SD of three independent experiments.

Abbreviations: DOX, doxorubicin; GO, graphene oxide; GO/DOX, GO loaded with DOX; SD, standard deviation.

with the advancement of cytogenetics and molecular biology, prolonging the overall survival rate and improving the prognosis of MM. However, MM remains a difficult-to-control hematologic malignancy.

Nanodrug research has become the focus of modern medicine, as nanodrug carriers can increase the biocompatibility of drugs and reduce their adverse effects. Many nanodrugs have proven clinical success in hematological malignancy, including liposomal DOX, which has been found to significantly decrease cardiotoxicity and increase therapeutic efficacy. ${ }^{9,30}$ It is necessary to better understand this new nanodrug carrier.

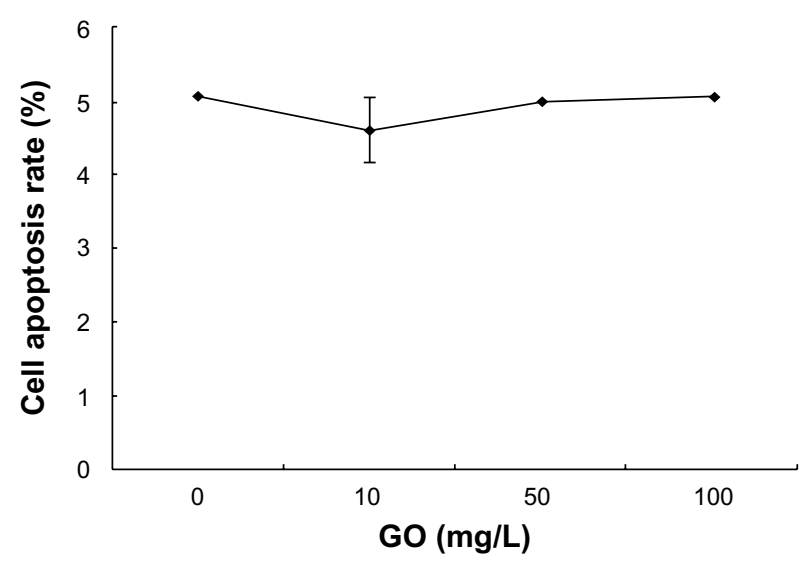

Figure 6 The effect of GO $(10,50$, and $100 \mathrm{mg} / \mathrm{L}$; size $<100 \mathrm{~nm})$ on apoptosis of RPMI-8226 cells for 24 hours.

Abbreviation: GO, graphene oxide.
Inorganic nanomaterials are of particular interest as drug carriers because of their good stability, high yield, and low cost. The new carbon nanomaterial, GO, was successfully prepared in 2004, and several studies have found GO to be a suitable drug carrier. ${ }^{14,18,31}$ Nevertheless, there have been no reports on the toxic effects of GO and the antitumor effects of GO/DOX on human MM cells

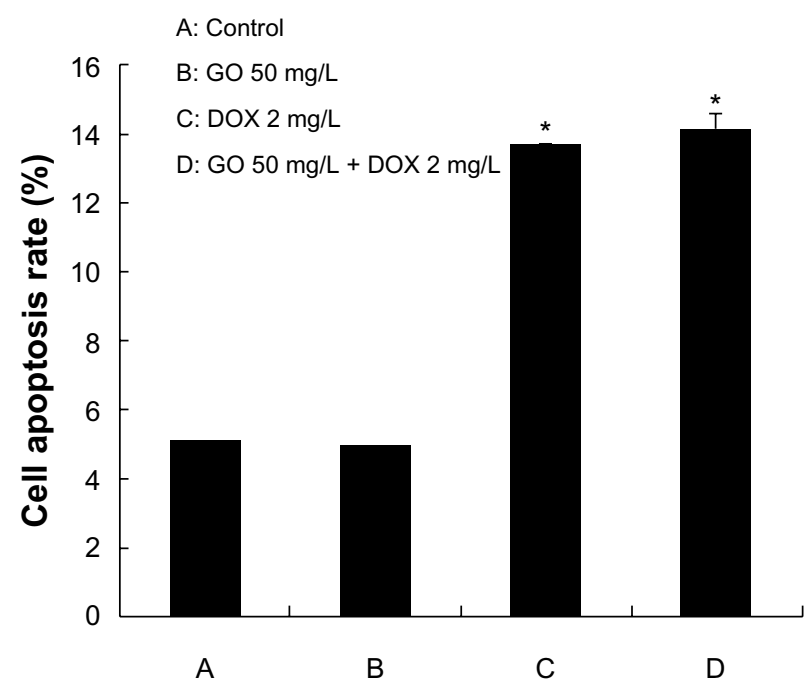

Figure 7 The effect of GO, DOX, and GO/DOX on apoptosis of RPMI-8226 cells for 24 hours.

Notes: Each bar represents the mean \pm SD of three independent experiments. $* P<0.05$ denotes significant differences between mean values measured in the DOX and GO/DOX group and that in control group.

Abbreviations: DOX, doxorubicin; GO, graphene oxide; GO/DOX, GO loaded with DOX; SD, standard deviation. 


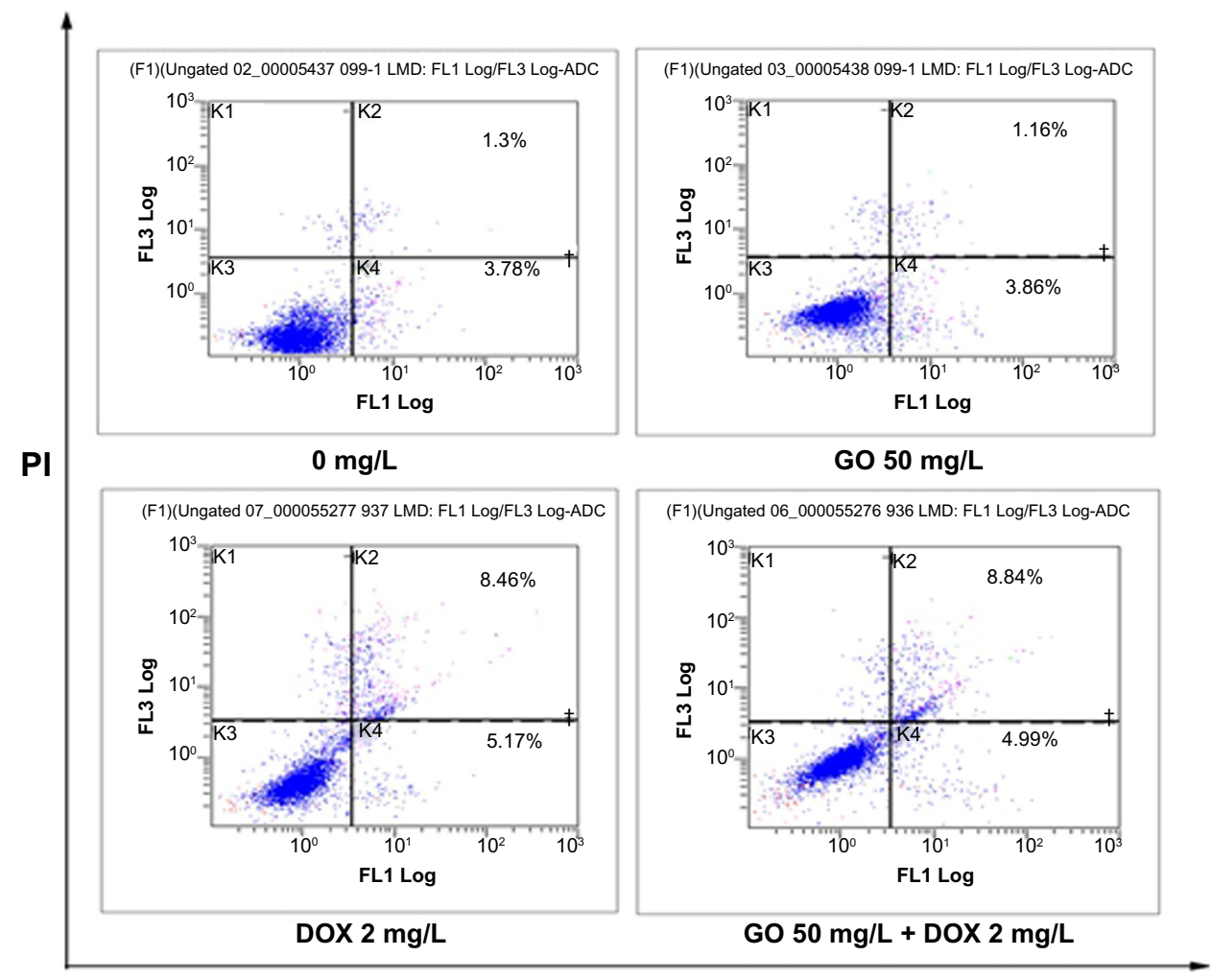

Annexin V-FITC

Figure 8 Flow cytometric analysis of apoptotic RPMI-8226 cells for 24 hours. RPMI-8226 cells treated for indicated time periods with $0 \mathrm{mg} / \mathrm{L}, \mathrm{GO} 50 \mathrm{mg} / \mathrm{L}, \mathrm{DOX} 2 \mathrm{mg} / \mathrm{L}$, and GO/DOX (GO $50 \mathrm{mg} / \mathrm{L}+$ DOX $2 \mathrm{mg} / \mathrm{L})$. Cells were harvested, promptly stained with annexin V-FITC, and analyzed on a flow cytometer (Cytomic ${ }^{\mathrm{TM}}$ FC500; Beckman Coulter, Miami, FL, USA). Scattergrams from a representative experiment are shown.

Abbreviations: DOX, doxorubicin; FITC, fluorescein isothiocyanate; GO, graphene oxide; GO/DOX, GO loaded with DOX.

(RPMI-8226). In the present study, we focused particularly on the cytotoxicity of GO and GO/DOX on MM RPMI8226 cells.

Our results found that GO treatment resulted in a dose-dependent inhibition of cell growth in RPMI-8226 cells and that GO was not highly toxic to MM cells. This was similar to the results of Chang et al, ${ }^{26}$ in which the cell viability of GO-treated A549 cells at lower concentrations was the same as that of the control cells. ${ }^{26}$ Their research also found that GO statistically significantly increases intracellular reactive oxygen species (ROS) ${ }^{26}$ Oxidative stress is a well-recognized toxicological mechanism of various nanoparticles. ${ }^{32}$ One study found that GO induced ROS generation in A549 cells, but no obvious toxicity was observed. ${ }^{26}$ Another study also found GO induced ROS generation in Hep G2 cells. ${ }^{33}$ It can be concluded that the low cytotoxicity of GO may be due to ROS generation, but the precise mechanism is vague.

Flow cytometry analysis of annexin V-FITC staining revealed that GO/DOX and DOX increased the apoptotic populations of RPMI-8226 cells, although there was no significant differences between the GO/DOX- and DOX-treated cells $(P>0.05)$. However, GO did not affect the ability of
DOX to induce cell apoptosis, and GO did not induce cell apoptosis in RPMI-8226 cells. These results confirmed the apoptotic effects of DOX and show that GO did not induce cell apoptosis or affect the ability of DOX to induce cell apoptosis. There are few studies on the cell apoptosis of GO. Li et $\mathrm{a}^{22}$ and Vallabani et $\mathrm{al}^{25}$ found that exposure of cells to graphene caused an increase in the proportion of cell apoptosis. Thus, the low cytotoxicity of GO might have been produced by oxidative stress. ${ }^{26}$

In cell-cycle analysis using PI staining, we observed that the cell cycle was not arrested at the $\mathrm{G}_{0} / \mathrm{G}_{1}$ phase after 24 hours of treatment in RPMI-8226 cells. This confirms that GO did not affect the cell cycle of RPMI-8226 cells and, as a result, may be a suitable nanocarrier for transporting anticancer drugs against hematological malignant cells.

In conclusion, we examined the toxic effects of GO using RPMI-8226 cells and found that GO caused low cytotoxicity, could not induce cell apoptosis, and did not affect the antitumor effects of DOX. Therefore, GO has high biocompatibility and can be used efficiently with DOX.

To the best of the authors' knowledge, no study has been reported thus far elaborating on the effects of GO, DOX, and 
GO/DOX on RPMI-8226 cells. Our findings prove that GO is suitable as a nanocarrier of anticancer drugs, with potentially successful application in hematological malignancy therapy in the future.

\section{Conclusion}

In the present study, we used RPMI-8226 cells to assess the effects of GO and GO/DOX on hematological tumor cells. CCK-8 assay data found that GO caused low cytotoxicity in RPMI-8226 cells and that GO/DOX was more cytotoxic than pure DOX at the same concentration. When the cell viability impact of GO was removed, there were no significant differences between GO/DOX- and DOX-treated cells. The main form of cell death with GO/DOX and DOX was cell apoptosis. These results indicate that GO did not decrease antitumor activity of DOX. Furthermore, the study found that GO did not induce apoptosis nor alter the cell cycle in RPMI-8226 cells. These results demonstrate that GO may be a highly biocompatible nanomaterial with practical applications in the therapy of hematological malignancy. Although the clinical significance of our findings remains to be elucidated, the information may contribute to a better understanding of the interactions between MM cells and GO nanomaterials.

\section{Acknowledgments}

This work was supported by Natural Science Foundation of Qingdao (12-1-4-2-23-jch), Science and Technology Development Program of Shandong Province, People's Republic of China (2012GSF111819). We thank the anonymous reviewers for their helpful suggestions on the quality improvement of our paper.

\section{Disclosure}

The authors report no conflicts of interest and have no financial interests to declare. The content and writing of this paper was carried out solely by the listed authors.

\section{References}

1. Kyle RA, Rajkumar SV. Multiple myeloma. N Engl J Med. 2004;351: 1860-1873.

2. Brenner H, Gondos A, Pulte D. Recent major improvement in longterm survival of younger patients with multiple myeloma. Blood. 2008;111(5):2521-2526.

3. Michel A, Jean-Luc H, Anne-Marie S, et al. A prospective, randomized trial of autologous bone marrow transplantation and chemotherapy in multiple myeloma. N Engl J Med. 1996;335:91-97.

4. Anderson Kenneth C. Multiple myeloma: how far have we come? Mayo Clin Proc. 2003;78(1):15-17.

5. Geneviève AS, Danielle LG. Daunorubicin and doxorubicin, anthracycline antibiotics, a physicochemical and biological review. Biochimie. 1984;66(5):333-352.
6. Speth PA, van Hoesel QG, Haanen C. Clinical pharmacokinetics of doxorubicin. Clin Pharmacokinet. 1988;15(1):15-31.

7. Tulubas F, Gurel A, Oran M, Topcu B, Caglar V, Uygur E. The protective effects of $\omega$-3 fatty acids on doxorubicin-induced hepatotoxicity and nephrotoxicity in rats. Toxicol Ind Health. Epub March 19, 2013.

8. El-SheikhAA, Morsy MA, Mahmoud MM, Rifaai RA, AbdelrahmanAM. Effect of coenzyme-q10 on doxorubicin-induced nephrotoxicity in rats. Adv Pharmacol Sci. 2012;2012:981461.

9. Lyseng-Williamson KA, Duggan ST, Keating GM. Pegylated liposomal Doxorubicin: a guide to its use in various malignancies. BioDrugs. 2013;27(5):533-540.

10. Khan MFS, Alexander AB. Thermal properties of graphene and multilayer graphene: applications in thermal interface materials. Solid State Commun. 2012;152(15):1331-1340.

11. Lian P, Zhu X, Liang S, Li Z, Yang W, Wang H. High reversible capacity of $\mathrm{SnO}_{2}$ /graphene nanocomposite as an anode material for lithium-ion batteries. Electrochim Acta. 2011;56(12):4532-4539.

12. Gao Y, Li Y, Zhang L, et al. Adsorption and removal of tetracycline antibiotics from aqueous solution by graphene oxide. $J$ Colloid Interf Sci. 2012;368(1):540-546.

13. Premkumar T, Geckeler KE. Graphene-DNA hybrid materials: assembly, applications, and prospects. Prog Polym Sci. 2012;37(4): 515-529.

14. Depan D, Shah J, Misra RDK. Controlled release of drug from folatedecorated and graphene mediated drug delivery system: synthesis, loading efficiency, and drug release response. Mater Sci Eng C. 2011;31(7):1305-1312.

15. Liu Z, Robinson JT, Tabakman SM, Yang K, Dai H. Carbon materials for drug delivery and cancer therapy. Mater Today. 2011;14(7-8): 316-323.

16. Markovic ZM, Harhaji-Trajkovic LM, Todorovic-Markovic BM, et al. In vitro comparison of the photothermal anticancer activity of graphene nanoparticles and carbon nanotubes. Biomaterials. 2011;32(4): $1121-1129$.

17. Wang Z, Gao Y, Xia J, Zhang F, Xia Y, Li Y. Synthesis and characterization of glycyrrhizin-decorated graphene oxide for hepatocyte-targeted delivery. C R Chim. 2012;15(8):708-713.

18. Wu S, Zhao X, Li Y, et al. Adsorption properties of doxorubicin hydrochloride onto graphene oxide: equilibrium, kinetic and thermodynamic studies. Materials. 2013;6(5):2026-2042.

19. Zhao GX, Li JX, Wang XK. Kinetic and thermodynamic study of 1-naphthol adsorption from aqueous solution to sulfonated graphene nanosheets. Chem Eng J. 2011;173(1):185-190.

20. Pan B, Xing B. Adsorption mechanisms of organic chemicals on carbon nanotubes. Environ Sci Technol. 2008;42(24):9005-9013.

21. Pan B, Xing B. Adsorption of phenolic compounds by carbon nanotubes: role of aromaticity and substitution of hydroxyl groups. Environ Sci Technol. 2008;42(19):7254-7259.

22. Li Y, Liu Y, Fu Y, et al. The triggering of apoptosis in macrophages by pristine graphene through the MAPK and TGF-beta signaling pathways. Biomaterials. 2012;33(2):402-411.

23. Zhou H, Zhao K, Li W, et al. The interactions between pristine graphene and macrophages and the production of cytokines/chemokines via TLRand NF-KB-related signaling pathways. Biomaterials. 2012;33(29): 6933-6942.

24. Akhavan O, Ghaderi E, Akhavan A. Size-dependent genotoxicity of graphene nanoplatelets in human stem cells. Biomaterials. 2012;33(32): 8017-8025.

25. Vallabani NV, Mittal S, Shukla RK, et al. Toxicity of graphene in normal lung cells (BEAS-2B). J Biomed Nanotechnol. 2011;7(1):106-107.

26. Chang Y, Yang ST, Liu JH, et al. In vitro toxicity evaluation of graphene oxide on A549 cells. Toxicol Lett. 2011;200(3):201-210.

27. Wojtoniszak M, Chen X, Kalenczuk RJ, et al. Synthesis, dispersion, and cytocompatibility of graphene oxide and reduced graphene oxide. Colloid Surface B. 2012;89(1):79-85.

28. Liu JH, Yang ST, Wang H, et al. Effect of size and dose on the biodistribution of graphene oxide in mice. Nanomedicine. 2012;7(12): $1801-1812$. 
29. Yang K, Wan J, Zhang S, Zhang Y, Lee ST, Liu Z. In vivo pharmacokinetics, long-term biodistribution, and toxicology of PEGylated graphene in mice. ACS Nano. 2011;5(1):516-522.

30. Gabizon A, Shmeeda H, Barenholz Y. Pharmacokinetics of pegylated liposomal doxorubicin: review of animal and human studies. Clin Pharmacokinet. 2003;42(5):419-436.

31. Ni Y, Zhang F, Kokot S. Graphene oxide as a nanocarrier for loading and delivery of medicinal drugs and as a biosensor for detection of serum albumin. Analytica Chimica Acta. 2013;969(1):40-48.
32. Lewinski N, Colvin V, Drezek R. Cytotoxicity of nanoparticles. Small. 2008;4(1):26-49.

33. Lammel T, Boisseaux P, Fernández-Cruz M, Navas JM. Internalization and cytotoxicity of graphene oxide and carboxyl graphene nanoplatelets in the human hepatocellular carcinoma cell line HepG2. Part Fibre Toxicol. 2013;10:27.
International Journal of Nanomedicine

\section{Publish your work in this journal}

The International Journal of Nanomedicine is an international, peerreviewed journal focusing on the application of nanotechnology in diagnostics, therapeutics, and drug delivery systems throughout the biomedical field. This journal is indexed on PubMed Central,

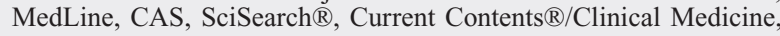

\section{Dovepress}

Journal Citation Reports/Science Edition, EMBase, Scopus and the Elsevier Bibliographic databases. The manuscript management system is completely online and includes a very quick and fair peer-review system, which is all easy to use. Visit http://www.dovepress.com/ testimonials.php to read real quotes from published authors.

Submit your manuscript here: http://www.dovepress.com/international-journal-of-nanomedicine-journal 